\title{
Россия и буддийский мир глазами молодежи Тувы, Бурятии и Калмыкии (по материалам социологического опроса)"
}

\author{
Валерий Н. Бадмаев, Мерген С. Уланов \\ Калмыцкий государственный университет имени Б. Б. Городовикова, Российская Федерация, \\ Чимиза К. Ламажаа \\ Московский гуманитарный университет; Калмыцкий \\ государственный университет имени Б. Б. Городовикова, Российская Федерация,

\section{Ульяна П. Бичелдей} \\ Тувинский институт гуманитарных и прикладных социально-экономических \\ исследований при Правительстве Республики Тыва, Российская Федерация, \\ Владимир И. Антонов, Оюуна А. Очирова \\ Восточно-Сибирский государственный университет технологий \\ и управления, Российская Федерация
}

В статье представлены результаты социологического исследования сентября-октября 2019 г. 709 студентов трех российских вузов в Туве, Бурятии и Калмыкии. Молодежь трех традиционно буддийских регионов опрашивалась по вопросам ее отношения к религии, к буддизму в частности. Ответы проанализированы сквозь призму идентичностей респондентов: российской, этнической, религиозной.

Молодежь рассматривает религиозность прежде всего как следование духовно-нравственным ценностям, понимает ценностно-регулятивный аспект религиозной жизни и ее связь с духовной жизнью всего общества. Россия понимается большинством респондентов как евразийское государство, объединяющее в себе и европейские, и азиатские народы и культуры. В целом, отношение у молодежи к буддизму положительное. Но он далеко не всеми понимается как неотъемлемая часть культуры страны, есть разногласия и по поводу термина «российский буддизм». Регионы, где они живут и обучаются, студенты более определенно называют буддийскими, а вот в отношении других - не столь уверены в этом. Стало очевидно, что среди молодежи знания вопросов истории религии в целом (и истории буддизма в частности) не слишком четкие.

Исследование показывает, что высокая религиозная идентификация молодежи имеет достаточно декларативный характер, нуждается в дополнительных исследованиях.

Ключевые слова: Россия; буддийский мир; российская молодежь; студент; Тува; Бурятия; Калмыкия; буддизм; буддийская культура; буддийский регион; религиозная идентичность; самоидентификация молодежи; религиозность

* Статья подготовлена при финансовой поддержке Российского научного фонда в рамках научного проекта «Россия и буддийский мир в дискурсе философского востоковедения» (грант № 19-18-00118).

\section{Для цитирования:}

Бадмаев В. Н., Уланов М. С., Ламажаа Ч. К.,Бичелдей У. П., Антонов В. И., Очирова О. А. Россия и буддийский мир глазами молодежи Тувы, Бурятии и Калмыкии (по материалам социологического опроса) [Электронный ресурс] // Новые исследования Тувы. 2020, № 1. URL: https://nit.tuva.asia/nit/article/view/... (дата обращения: дд.мм.гг.). DOI: 10.25178/nit.2020.1.3
} рологии Калмыцкого государственного университета имени Б. Б. Городовикова. Адрес: 358000, Россия, г. Элиста, ул. Пушкина, д. 11, каб. 111. Тел.: +7 (961) 844-37-73. Эл. адрес: badmav07@yandex.ru ORCID ID: 0000-0003-1066-8314

Уланов Мерген Санджиевич - доктор философских наук, кандидат исторических наук, доцент, профессор кафедры философии и культурологии Калмыцкого государственного университета имени Б. Б. Городовикова. Адрес: 358000, Россия, г. Элиста, ул. Пушкина, д. 11, каб. 111. Тел.: +7(961) 541-11-38. Эл. адрес: ulanov1974@mail.ru ORCID ID: 0000-0002-6749-7424

Ламажаа Чимиза Кудер-ооловна - доктор философских наук, заместитель директора по научной работе Института фундаментальных и прикладных исследований Московского гуманитарного университета; приглашенный исследователь Калмыцкого государственного университета имени Б. Б. Городовикова. Адрес: 111395, Россия, г. Москва, ул. Юности, д. 5, корп. 6, каб. 18. Тел.: +7 (499) 374-73-90. Эл. адрес: lamazhaа@tuva.asia ORCID ID: 0000-0003-1813-3605

Бичелдей Ульяна Павловна - доктор религиоведения (PhD), руководитель научно-исследовательской группы религиоведения Тувинского института гуманитарных и прикладных социально-экономических исследований при Правительстве Республики Тыва. Адрес: 66700, Россия, г. Кызыл, ул. Кочетова, д. 4. Тел.: +7 (394-22) 2-39-36. Эл. адрес: opei-ool@yandex.ru ORCID ID: 0000-0001-5588-9167

Антонов Владимир Иосифович - доктор философских наук, профессор, профессор кафедры философии, истории и культурологии Восточно-Сибирского государственного университета технологий и управления. Адрес: 670013, Россия, г. Улан-Удэ, ул. Ключевская, д. 40B, стр. 1. Тел.: +7 (914) 984-11-11. Эл. адрес: wlanto50@mail.ru ORCID ID: 0000-0001-9920-0667

Очирова Оюуна Анатольевна - доктор социологических наук, профессор, профессор кафедры «Социальные технологии» Восточно-Сибирского государственного университета технологий и управления. Адрес: 670013, Россия, г. Улан-Удэ, ул. Ключевская, д. 40B, стр. 1. Тел.: +7 (914) 052-21-56. Эл. адрес: sociologm@mail.ru ORCID ID: 0000-0002-8376-4086 


\title{
Russia and the Buddhist world through the eyes of the youth in Tuva, Buryatia and Kalmykia: a sociological survey and its outcomes"
}

\author{
Valeriy N. Badmaev, Mergen S. Ulanov \\ Kalmyk State University, Russian Federation, \\ Chimiza K. Lamazhaa \\ Moscow University for the Humanities; Kalmyk State University, Russian Federation, \\ Ulyana P. Bicheldey \\ Tuvan Institute for the Humanities and Applied Social and Economic Studies, Russian Federation, \\ Vladimir I. Antonov, Oyuna A. Ochirova \\ East Siberian State University of Technology and Management, Russian Federation
}

The article presents the outcomes of a sociological study held in September and October 2019, with 709 students of three universities in Tuva, Buryatia and Kalmykia as its respondents. The youth of the three regions of Russia where Buddhism is a prevailing religion was asked questions on their attitudes to religion, and Buddhism in particular. Their responses were collated with their own mix of identities as Russian citizens of a certain ethnic background and religious preferences.

Seeing religiosity primarily as following a set of spiritual and moral principles, the youth focuses on values and regulations of religious life of an individual and its connection to the spirituality of society in general.

Most respondents see Russia as a Eurasian state uniting both European and Asian peoples and cultures. On the whole, their attitude to Buddhism is positive, but few see this religion as an integral part of Russia's culture, and there are also disagreements on what "Russian Buddhism" may mean. While respondents are certain that the region they live and study in can be described as Buddhist, they are far from sure when it comes to Russia's other territories. It has become evident that the youth has only a superficial knowledge of history of religions, including the history of Buddhism.

The study has shown that the high degree of religious self-identification among youth is rather declarative and requires further in-depth studies.

Keywords: Russia; Buddhist world; youth in Russia; student; Tuva; Buryatia; Kalmykia; Buddhism; Buddhist culture; Buddhist region; religious identity; self-identification of youth; religiosity

"The article was prepared with support from the Russian Science Foundation, Grant No. 19-18-00118, «Russia and the Buddhist world in the discourse of the philosophy of Oriental Studies».

\section{For citation:}

Badmaev V. N., Ulanov M. S., lamazhaa Ch. K., Bicheldey U. N., Antonov V. I. and Ochirova O. A. Russia and the Buddhist world through the eyes of the youth in Tuva, Buryatia and Kalmykia: a sociological survey and its outcomes. The New Research of Tuva, 2020, no. 1 [online] Available at: https://nit.tuva.asia/nit/article/view/904 (access date: ...). DOI: $10.25178 /$ nit.2020.1.3

Badmaev Valeriy Nikolaevich, Doctor of Philosophy, Professor, Department of Philosophy and Cultural Studies, Kalmyk State University. Postal address: Office 111, 11 Pushkin St., 358000 Elista, Russian Federation. Tel.: +7 (961) 844-37-73. E-mail: badmav07@yandex.ru

Ulanov Mergen Sandzhievich, Doctor of Philosophy, Candidate of History, Professor, Department of Philosophy and Cultural Studies, Kalmyk State University. Postal address: Office 111, 11 Pushkin St., 358000 Elista, Russian Federation. Tel.: +7 (961) 541-11-38.E-mail: ulanov1974@mail.ru

Lamazhaa Chimiza Kuder-oolovna, Doctor of Philosophy, Deputy Director, Institute of Fundamental and Applied Studies, Moscow University for the Humanities; Visiting Researcher, Kalmyk State University. Postal address: 5 Yunosti St., 111395 Moscow, Russian Federation. Tel.: +7 (499) 374-73-90.E-mail: lamazhaa@tuva.asia

Bicheldey Ulyana Pavlovna, Doctor of Religious studies (Ph.D), Head, Religious studies unit, Tuvan Institute for the Humanities and Applied Social and Economic Studies. Postal address: 4 Kochetov St., 667000 Kyzyl, Russian Federation. Tel. +7 (394-22) 2-39-36. E-mail: opei-ool@yandex.ru

Antonov Vladimir Iosifovich, Doctor of Philosophy, Professor, Professor of the Department of Philosophy, History and Cultural studies, East Siberian State University of Technology and Management. Postal address: 40B Bldg. 1, Klyuchevskaya str., 670013 UlanUde, Russian Federation. Tel.: +7 (914) 984-11-11.E-mail: wlanto50@mail.ru

Ochirova Oyuna Anatolyevna, Doctor of Sociology, Professor, Department of Social technologies, East Siberian State University of Technology and Management. Postal address: 40B Bldg. 1, Klyuchevskaya str., 670013 Ulan-Ude, Russian Federation. Tel.: +7 (914) 052-21-56.E-mail: sociologm@mail.ru 


\section{Введение}

Популярность и значимость буддизма в современном культурно-конфессиональном ландшафте глобального мира продолжает расти (Уланов, 2007; Урбанаева, 2012: 126; Базаров, 2015). При этом буддизм все активнее выходит за рамки своих прежних локально-исторических и национальногеографических границ, он охватывает все новые культурные ареалы, т. е. происходит де-территориализация религии, ее транснационализация. Буддизм становится религией свободного выбора индивидов, его начинают рассматривать как один из ресурсов на свободном рынке религий (Варнавский, 2011: 194), как фактор межкультурного взаимодействия и диалога (Буддизм в контексте ... , 2015).

Расширение и увеличение значимости буддийского мира (территорий, население которых традиционно исповедует буддизм - государств или отдельных регионов государств; отдельных локальных общин, организаций и даже персон) идет не только экстенсивным путем. Общий рост значения религии также выражает собой и ответы локальных культур на вызовы глобализации (Базаров, 2014), когда усиливающееся влияние чужеродных культур оборачивается стремлением сообееств сохранять и развивать свои традиции, в том числе религиозные. При этом, как полагает академик РАН Б. В. Базаров, важна роль буддизма «в решении проблемы соотношения традиционных ценностей и ценностей XXI в., обусловленных современными высокими технологиями и широкой информатизацией, которые создают благодатную почву для беспрепятственного взаимопроникновения культур, навязывания чужих ценностей и чужого образа жизни. Важно понять, в какой степени философско-этические принципы, религиозная установка буддизма смогут стать гарантом сохранения традиционных ценностей, обеспечить их адаптацию к новым реалиям третьего тысячелетия?» (Базаров, 2015: 12).

Соответственно, исследование особенностей современного буддийского мира выходит за рамки религиоведческого дискурса и включает в себя исследование социокультурных феноменов, а также их осмысление как представителями академической науки, так и общественностью, причем разными поколениями. Особый интерес приобретает изучение мотиваций религиозного выбора, отношения к религии как традиционному вероисповеданию в исконно буддийских регионах и понимание буддистами связей между территориями. В России такими регионами являются республики Тува, Бурятия, Калмыкия, а также ряд областей, краев.

Исследовательский интерес группы ученых обращен к молодому поколению населения названных республик. Известно, что молодежь представляет собой особую социально-демографическую группу населения, которая особенно восприимчива к изменениям духовно-нравственных ценностей. Источниками ее ценностных ориентиров могут быть как традиционные социокультурные институты, так и новые. Соответственно, ее мнение может складываться в сочетании различных социокультурных установок, а также может определять тенденции религиозности населения. Исследования последних лет указывают на тот факт, что религиозность населения характеризуется устойчивой положительной динамикой, в том числе за счет роста молодежи, которая считает себя буддистами (например, в Туве 83\% молодежи тувинской национальности называет себя буддистами, см. Анайбан, 2017: 169). Тем не менее, в представления современной молодежи входит не только признание авторитета религии, не только следование ее предписаниям. Интересно осмысление молодыми людьми роли религии в их жизни, понимание ими буддизма и буддийского мира. Такой ракурс мнения молодежи еще не исследовался, в том числе в плане общего и особенного в представлениях юношей и девушек сразу трех буддийских регионов.

Исходя из этого, коллектив исследователей во главе с профессором Калмыцкого государственного университета В.Н. Бадмаевым в сентябре - октябре 2019 г. при поддержке Российского научного фонда (по проекту «Россия и буддийский мир в дискурсе философского востоковедения») инициировали и провели одновременно в трех российских республиках - в Туве, Бурятии и Калмыкии социологическое исследование методом онлай-анкетирования (с помощью сервиса Google Forms), посвященное изучению представлений о буддизме и буддийском мире среди студенческой молодежи ${ }^{1}$.

${ }^{1}$ Следует отметить востребованность социологических исследований религии (Островская, 2018; Синелина, 2009; Социология религии, 2013; Энциклопедический словарь, 2017), вообще, и буддизма (Бадмацыренов, 2016; Бадмацыренов, Родионов, 2014; Намруева, 2012; Островская, 1999), в частности, в современном российском научном дискурсе. Российская социология религии, прошедшая свою институционализацию и обладающая «собственным теоретико-методологическим инструментарием и тематически разнообразными прикладными исследованиями религий современного общества» (Островская, 2018: 1-2), отличается также и развитием 
В исследовании приняли участие 709 студентов высших учебных заведений: Тувы - Тувинского государственного университета (г.Кызыл) - 224 чел., Бурятии - Восточно-Сибирского государственного университета технологий и управления (г. Улан-Удэ) - 251 чел., и Калмыкии - Калмыцкого государственного университета (г. Элиста) - 234 чел. ${ }^{1}$, как гуманитарных, так и естественнонаучных специальностей. Вид выборки исследования - целевая. Исследование по критерию самоопределения показало, что в двух из трех регионах большинство опрошенных студентов считает себя исповедующими буддизм: в Туве - 68,3\%; в Калмыкии - 62,8\%, а в Бурятии $-36,3 \%$.

Национальный состав выборки отразил примерно близкое соотношение национального состава населения регионов:

- в Туве тувинцев среди опрошенных оказалось 90,5\%, русских - 2,3\% (остальные ответившие называли себя не только представителями других национальностей, но и метисами, а также просто «россиянами», «буддистами» и пр.);

- в Бурятии бурятов насчиталось $40,5 \%$, русских $-45,2 \%$, остальных $-14,3 \%$,

- в Калмыкии калмыками назвались 70\% опрошенных, русскими - 9,7\%, остальные 20,3\% распределились на представителей других национальностей (таджики, украинцы, узбеки и пр.).

По возрастным подгруппам наиболее многочисленной во всех трех регионах оказалась молодежь в возрасте от 17 до 22 лет: Тува - 81,6\%, Бурятия - 81,3\%, Калмыкия - 87,3\%. Состав общей выборки по полу: юношей $-39 \%$, девушек $-61 \%$.

Представим в данной статье основные результаты этого опроса.

\section{Представление о религиозности}

Одним из основных пунктов анкеты был вопрос о том, что означает быть религиозным человеком. Распределение ответов респондентов на данный вопрос представлено в таблице 1.

Таблица 1. Ответы на вопрос «Что для Вас означает, прежде всего, быть религиозным человеком?», в \% от числа опрошенных по каждому из регионов.

Table 1. Responses to the question, “What does being religious primarily mean to you?”, \% of respondents by region.

\begin{tabular}{|c|l|c|c|c|}
\hline № & \multicolumn{1}{|c|}{ Вариант } & Тува & Бурятия & Калмыкия \\
\hline 1 & $\begin{array}{l}\text { Соблюдать человеческие и морально- } \\
\text { этические нормы }\end{array}$ & 76,8 & 61,4 & 68,8 \\
\hline 2 & $\begin{array}{l}\text { Молиться и посещать религиозные } \\
\text { места (мечети, церкви, храмы, хурулы, } \\
\text { хурээ, синагоги, священные места и } \\
\text { пр.) }\end{array}$ & 49,6 & 23,8 & 26,1 \\
\hline 3 & $\begin{array}{l}\text { Твердо придерживаться норм и } \\
\text { правил священных писаний (Коран, } \\
\text { Библия, Тора, Ганджур/Канчыыр и др.) }\end{array}$ & 19,6 & 19,1 & 26,9 \\
\hline 4 & $\begin{array}{l}\text { Ощущать себя представителем той } \\
\text { или иной религиозной группы }\end{array}$ & 20,1 & 1,2 & 2,6 \\
\hline 5 & Носить религиозную одежду & 2,2 & 15,1 & 20,9 \\
\hline 6 & $\begin{array}{l}\text { Выполнять необходимые религиозные } \\
\text { обряды в любом месте }\end{array}$ & 14,3 & 0,4 & 0,4 \\
\hline 7 & Свой вариант ответа & 0,8 & 10 & 5,6 \\
\hline 10 & Затрудняюсь ответить & 7,1 & \\
\hline
\end{tabular}

Прим.: Отмечать можно было несколько вариантов ответа. Также можно было вписать свой вариант ответа.

комплекса «направлений, концепций и отдельных исследований, который можно обозначить как буддийскую социологию» (Бадмацыренов, 2016: 181). Буддийская социология акцентирует внимание на то, на то, каким образом буддийская мысль и практика могут внести вклад в область социологического знания, в понимание социальных институтов, социальных проблем, а также динамики и возможностей социальных изменений (Bell, 1979; Schipper, 2012).

${ }^{1}$ Опросы в университетах проводились при любезном разрешении и содействии руководства вузов. См. раздел «Благодарности» в конце статьи. 
Распространенным остается мнение о том, что истинно верующий человек - это тот человек, который обязательно посещает храмы (хурээ, хурулы, дацаны, церкви, мечети в зависимости от вероисповедания верующего). Его разделяет практически половина из наших опрошенных в каждом регионе: Тува - 49,6\%; Бурятия - $47,8 \%$; Калмыкия $-52,1 \%$.

Тем не менее, наше исследование позволило констатировать, что для большинства студентов религиозность связана прежде всего с соблюдением общечеловеческих и морально-этических норм: Тува $76,8 \%$; Бурятия $-61,4 \%$; Калмыкия - 68,8\%. То есть, мнение о том, что самое важное в религиозном человеке - его приверженность в целом морали - превалирует над представлением о важности религиозной обрядности. Еще меньше мнений о том, что религиозный человек - тот, кто «твердо придерживается норм и правил священных писаний» (Тува $-19,6 \%$; Бурятия $-23,5 \%$; Калмыкия $26,1 \%)$. Примерно столько же набрал вариант ответа «Ощущать себя представителем той или иной религиозной группы»: Тува -- 20,1\%; Бурятия - 19,1\%; Калмыкия $-26,9 \%$.

Значительно меньшая часть респондентов связывает проявление веры с необходимостью выполнения религиозных обрядов в любом месте (Тува $-14,3 \%$; Бурятия $-15,1 \%$; Калмыкия $-20,9 \%$ ) и ношением религиозной одежды (Тува $-2,2 \%$; Бурятия $-1,2 \%$; Калмыкия $-2,6 \%$ ).

Соответственно, мы видим, что молодежь рассматривает религиозность прежде всего как следование духовно-нравственным ценностям, понимает ценностно-регулятивный аспект религиозной жизни. И этот факт отраден особенно в свете регулярно высказываемого пожелания Его Святейшества Далай-ламы XIV, о котором пишет Р. Турман: «Уже много лет тому назад он сказал и всегда повторяет, что не желает обратить всех в буддизм. Он не хочет, чтобы все приняли буддизм, но при этом продолжали действовать эгоистически. Если вы просто номинально меняете свое вероисповедание, от этого нет особой пользы» (Турман, 2015: 22).

Существенных территориальных различий во мнениях мы здесь не получили, что подчеркивает значимость и общность мнения молодого поколения в традиционно буддийских территориях.

\section{Самоидентификация молодежи}

Последующие вопросы относительно буддизма и отношения молодых к нему мы посчитали необходимым выяснять, прежде всего, уточнив важность их самоидентификации - этнической, религиозной, государственной.

На вопрос «Кем Вы себя считаете прежде всего?» были предложены несколько вариантов ответов, которые надо было ранжировать - расставить в порядке убывания важности: от самого важного до менее важного.

Студенты из Тувы расположили свой выбор следующим образом: представителем своей национальности прежде всего себя считают $50,4 \%$; россиянами $-47,4 \%$; евразийцами $-35,7 \%$; представителями своей религии - 34,8\%; гражданами мира $-33,5 \%$ опрошенных.

Студенты Бурятии на первое место поставили национальную идентичность - 35,4\%; на второе место - евразийскую - 34,7\%; на третье место - российскую - 31,9\%; гражданами мира себя считают $28,7 \%$; представителями своей религии $-28,2 \%$.

Студенты Калмыкии сделали свой выбор в следующем порядке. Считают себя россиянами - 46\%; калмыками - 40,2\%; евразийцами - 39,3\%; гражданами мира - 39\%; представителями своей религии 38\% опрошенных.

Учитывая национальную идентификацию наших опрошенных (национальный состав выборки, представленный выше), мы можем отметить тот факт, что российская идентичность в среде молодежи национальных республик принимается и у значительной части даже является приоритетной (у учащихся Калмыкии это чуть более выражено). Однако, все же этническая идентичность является более приоритетной для студентов Тувы и Бурятии. В случае Тувы это вполне объяснимо, учитывая традиционно сильную региональную и этническую идентичность коренного населения республики (см. также: Leung, 2017). Бурятская картина мнений здесь нам представляется тоже достаточно очевидной: национальный состав региона, история культурного диалога в нем, геополитическое расположение все это способствует превалированию как этнической, так и евразийской идентичности молодежи. В данном случае можно говорить о феномене национально-цивилизационной идентичности, которая отличается как от национальной, так и от цивилизационной идентичности, и представляет собой «отождествление или соотнесение себя индивидами с определенной национально-цивилизационной 
общностью, т. е. такой общностью, которая одновременно имеет черты как нации, так и цивилизации, или же является промежуточным образованием между нацией и цивилизацией» (Пантин. 2017: 462). Мы полагаем, что вопрос иерархии идентичности российской молодежи в национальных регионах требует специального исследования.

Большинство наших опрошенных во всех трех регионах считают себя людьми, исповедующими какую-либо религию: Тува - 74,6\%; Бурятия - 70,1\%; Калмыкия - 71,9\%. Уточняющий вопрос о религии показал, что в двух республиках среди наших респондентов преобладают буддисты: Тува 68,3\%; Калмыкия - 62,8\%, а вот в Бурятии буддистов наш опрос насчитал только 36,3\% (помимо них было 34,4\% христиан, 20,3\% - тех, кто назвал себя «не верующими» и «атеистами», и тех, кто считает себя приверженцем иных конфессий).

Скорее всего, этот показатель не раскрывает точного положения вещей с религиозной идентичностью, которая «формируется в результате соотнесения себя с определенной религией и определяется значением веры и ролью религиозных институтов в его сознании и поведении», ее «можно рассматривать как результат самоотождествления личности или референтного сообщества с определенным религиозным учением или его частью» (Мчедлова, 2017: 335). Во многом, религиозную принадлежность, особенно молодые люди, начинают указывать по этническому принципу: раз я калмык, значит - буддист (см.: Филатов, Лункин, 2005).

В нашей работе мы не ставим целью установить истинное число буддистов среди опрошенных, полученный нами показатель лишь рассматривается как показатель самоидентификации молодежи, которая и достаточно свободно и активно «примеряет» на себя религиозную идентичность, и имеет желание рассуждать о религии.

\section{Общественные функции религии}

Учитывая тот факт, что молодежь стремится познавать мир, рассуждать о значимых социальных проблемах, составляя при этом свое мнение, исследователи поинтересовались ответами на вопрос «На какие сферы общества оказывает влияние религия?» (таб. 2).

Таблица 2. Ответы на вопрос «Как Вы считаете, на какие сферы общества оказывает влияние религия?», в \% от числа опрошенных по каждому из регионов.

Table 2. Responses to the question, "In your opinion, what areas of social life are influenced by religion?", \% of respondents by region.

\begin{tabular}{|l|l|c|c|c|}
\hline № & \multicolumn{1}{|c|}{ Вариант ответа } & Тува & Бурятия & Калмыкия \\
\hline 1 & $\begin{array}{l}\text { Духовно-нравственное } \\
\text { состояние общества }\end{array}$ & 83 & 75,3 & 80,8 \\
\hline 2 & Семья & 53,6 & 49,8 & 55,6 \\
\hline 3 & Межнациональные отношения & 37,1 & 37,8 & 51,7 \\
\hline 4 & $\begin{array}{l}\text { Внутренняя политика } \\
\text { государства }\end{array}$ & 12,5 & 17,5 & 17,9 \\
\hline 5 & Внешняя политика государства & 6,3 & 13,5 & 12,4 \\
\hline 6 & $\begin{array}{l}\text { Социально-экономическое } \\
\text { развитие общества }\end{array}$ & 7,6 & 14,3 & 15,8 \\
\hline 7 & $\begin{array}{l}\text { Не оказывает никакого влияния } \\
\text { ни на какие сферы общества }\end{array}$ & 1,8 & 4,4 & 2,6 \\
\hline 8 & Затрудняюсь ответить & 4,9 & 6,8 & 6,4 \\
\hline 9 & Свой вариант ответа & - & 0,4 & 0,4 \\
\hline
\end{tabular}

Прим.: Отмечать можно было несколько вариантов ответа. Также можно было вписать свой вариант ответа.

Большинство опрошенных во всех трех регионах сошлось на том, что религия оказывает влияние прежде всего на духовно-нравственное состояние общества: Тува - 83\%; Бурятия - 75,3\%; Калмыкия 80,8\%. Второй по значимости социальный институт, испытывающий на себе влияние религии - семья: 
Тува $-53,6 \%$; Бурятия - 49,8\%; Калмыкия - 55,6\%. Третья значимая сфера - межнациональные отношения: Тува $-37,1 \%$; Бурятия $-37,8 \%$; Калмыкия $-51,7 \%$.

Политика государства, как внутренняя, так и внешняя, социально-экономическое развитие страны, по мнению молодых, очень мало зависят от религии. Были также и немногочисленные мнения о том, что религия ни на какие сферы не влияет, были и затруднившиеся с ответами.

Ранжирование сфер, полученное в результате опроса, с одной стороны, практически повторяет порядок, который был предложен респондентам для выбора в анкете на данный вопрос. Соответственно, мы можем предположить, что на результат в определенной степени повлияло исследовательское ранжирование сфер.

Тем не менее, общий итог, практически совпадающий по трем регионам, показывает нам реальную тенденцию, особенно во взаимосвязи с ответами на предыдущий вопрос. Как видно, большинство молодежи связывает религию с духовным состоянием общества, с жизнью семьи, со сферой межнациональных отношений.

\section{Цивилизационная идентичность России}

Вопрос, связанный с цивилизационной идентичностью России («Какой тезис представляется Вам наиболее верным» с выбором одного из предложенных вариантов ответа), дал нам следующую картину мнений (см. таб. 3).

Два «крайних» варианта ответа «Россия, прежде всего, - это часть Европы» и «Россия, прежде всего часть Азии» была поддержана лишь небольшой частью опрошенных. При этом особый географический «перекос» становится очевиден, учитывая подавляющее этническое большинство опрошенных в Туве. $11,2 \%$ респондентов из этой республики (против 1,6\% в Бурятии и 0,9\% - в Калмыкии) считают, что Россия - прежде всего часть Азии, а иной вариант (Россия - часть Европы) здесь же получил относительно меньшее число голосов (5,4\%, тогда как в Бурятии это $-7,2$ и в Калмыкии $-7,7 \%)$.

Таблица 3. Ответы на вопрос «Какой тезис представляется Вам наиболее верным?», в \% от числа опрошенных по каждому из регионов.

Table 3. Responses to the question, "Which of these statements seem true to you?”, \% of respondents by region

\begin{tabular}{|c|l|c|c|c|}
\hline № & \multicolumn{1}{|c|}{ Вариант ответа } & Тува & Бурятия & Калмыкия \\
\hline 1 & $\begin{array}{l}\text { Россия исторически и } \\
\text { географически формировалась } \\
\text { как евразийское государство, } \\
\text { объединяюе в себе и } \\
\text { европейские, и азиатские } \\
\text { народы и культуры }\end{array}$ & 62,1 & 63,3 & 7,7 \\
\hline 2 & $\begin{array}{l}\text { Россия, прежде всего, - это часть } \\
\text { Европы }\end{array}$ & 5,4 & 7,2 & 0,9 \\
\hline 3 & $\begin{array}{l}\text { Россия, прежде всего, это часть } \\
\text { Азии }\end{array}$ & 11,2 & 26,3 & 30,7 \\
\hline 4 & $\begin{array}{l}\text { Россия - это самобытная } \\
\text { цивилизация, не похожая ни на } \\
\text { Запад, ни на Восток }\end{array}$ & 21,3 & 1,6 & 100 \\
\hline 5 & Свой вариант ответа & 100 & 100 & \\
\hline 6 & Итого & - & & 7,6 \\
\hline
\end{tabular}

Наиболее популярным мнением во всех трех регионах стало высказывание «Россия исторически и географически формировалась как евразийское государство, объединяющее в себе и европейские, и азиатские народы и культуры»: Тува $-62,1 \%$, Бурятия $-63,3 \%$ и Калмыкия $-60,7 \%$. Представление о том, что наша страна объединяет народы, очевидно, превалирует над вторым по популярности мнением о том, что «Россия - это самобытная цивилизация, не похожая ни на Запад, ни на Восток»: Тува $-21,3 \%$; Бурятия $-26,3 \%$; Калмыкия $-30,7 \%$. 
Несмотря на то, что оба высказывания делают акцент на своеобразии России, тем не менее, большинство молодежи понимает разницу между двумя характеристиками и отдает предпочтение той, где речь идет об объединении культурных начал, а не об их отрицании.

\section{Буддизм и Россия}

На вопрос «Как Вы относитесь к утверждению, что буддизм - это органичная, неотъемлемая часть российской истории, исторического наследия народов России?» большинство респондентов ответили положительно во всех трех регионах: в Туве - 70,1\%; в Бурятии - 71,3\%; в Калмыкии - 75,3\% (таб. 4).

Таблица 4. Ответы на вопрос «Как Вы относитесь к утверждению, что буддизм - это органичная, неотъемлемая часть российской истории, исторического наследия народов России?», в \% от числа опрошенных по каждому из регионов.

Table 4. Responses to the question, "Do you agree that Buddhism is an integral part of Russian history and the heritage of the peoples of Russia?", \% of respondents by region.

\begin{tabular}{|c|c|c|c|c|}
\hline № & Вариант ответа & Тува & Бурятия & Калмыкия \\
\hline 1 & Да, согласен & 70,1 & 71,3 & 75,3 \\
\hline 2 & Нет, не согласен & 29 & 24,7 & 21,9 \\
\hline 3 & Свой вариант ответа & 0,9 & 3,2 & 2,8 \\
\hline 4 & ИТОгО & 100 & 100 & 100 \\
\hline
\end{tabular}

В то же время определенная часть опрошенных, чуть более или почти четверть опрошенных (в Туве - 29\%; в Бурятии - 24,7\%; в Калмыкии - 21,9\%) не считает буддизм неотъемлемой частью российской культуры.

С одной стороны, этот факт удивляет, учитывая как то, что опрос проводился в традиционно буддийских регионах, так и то, что среди опрошенных, по крайней мере в Туве и Калмыкии, значительное число приверженцев буддийской религии. Но, с другой стороны, если мы сопоставим эту картину мнений с ответами на вопрос о преимущественной самоидентификации молодежи, то мы можем понять этот парадокс. Если российская идентичность у молодежи не в приоритете (считают себя прежде всего россиянами: Тува $-47,4 \%$; Бурятия - 31,9\%; Калмыкия - 46\%, то есть менее половины опрошенных), то здесь имеет место не сколько представление «отчуждения» буддизма от России, сколько представление о некоторой собственной отчужденности от российского дискурса. Подобный факт недавно фиксировался в исследовании образа России у буддистов Тувы (см.: Шестопал, Смулькина, Сорозикова, 2019; см. об этом также: Ламажаа, 2019).

\section{Существует ли российский буддизм}

Безусловно, задавая студентам вопрос «Можно ли говорить о таком явлении, как российский буддизм?», мы осознавали, что ставим молодых респондентов перед сложной задачей, которую до сих пор решают исследователи и продолжают о ней дискутировать (говорим ли мы о российском буддизме в историческом аспекте или о доктринальных различиях; возможно ли вообе выделять как «российский буддизм», так и его локальные версии, типа «бурятский буддизм» и пр., см. Кузьмин, 2016).

Тем не менее, вопрос был задан и ответы на него отчасти отразили предыдущую картину мнений, когда буддизм не рассматривается определенной частью молодежи как неотъемлемая часть российской истории и культуры (см. таб. 5).

Таблица 5. Ответы на вопрос «Можно ли говорить о таком явлении, как российский буддизм?», в \% от числа опрошенных по каждому из регионов.

Table 5. Responses to the question, "Is there such a phenomenon as Russian Buddhism?”, \% of respondents by region.

\begin{tabular}{|c|c|c|c|c|}
\hline No & Вариант ответа & Тува & Бурятия & Калмыкия \\
\hline 1 & Да, согласен & 63 & 59 & 69 \\
\hline 2 & Нет, не согласен & 35 & 37,4 & 27,8 \\
\hline
\end{tabular}




\begin{tabular}{|c|c|c|c|c|}
\hline 3 & Не знаю, затрудняюсь ответить & 1,6 & 2,4 & 2,4 \\
\hline 4 & Свой вариант ответа & 0,4 & 1,2 & 0,8 \\
\hline 5 & ИТОГО & 100 & 100 & 100 \\
\hline
\end{tabular}

Значительная часть респондентов согласилась с трактовкой российского буддизма: Тува - 63\%; Бурятия - 59\%; Калмыкия - 69\%. Но в то же время треть опрошенных с этим определением не согласилась: Тува - 35\%; Бурятия - 37,4\%; Калмыкия - 27,8\%.

При этом другой вопрос на эту же тему («Какие регионы мира считаются регионами традиционного распространения буддизма?») показал, что Россию как подобной территорией считает лишь треть опрошенных в каждом регионе: Тува $-27,7 \%$, Бурятия $-31,5 \%$, Калмыкия $-27 \%$.

Необходимо уточнить термин «российский буддизм» в понимании авторов исследования: ему придается условный характер; и относится термин не к теологическим вопросам, не к доктринальным отличиям традиции, а к историческому и социокультурному явлению. Российские буддисты, в своем большинстве придерживаясь традиции буддийской школы Гэлуг (пришедшей из Тибета, где сохранилась тибетоязычная версия позднеиндийского буддизма Махаяны), тем не менее, не поменяли своих этнокультурных традиций, образа жизни, они проживают в иной политической и социальноэкономической ситуации, поэтому, безусловно, этнокультурная, цивилизационная идентичность россиян-буддистов позволяет им ощущать свое отличие от других буддистов Азии.

Наши студенты в качестве оснований для «легитимности» понятия «российский буддизм» выбрали следующие ответы на вопрос о конкретизации своего мнения:

- «Буддизм традиционно исповедуется российскими народами (буряты, калмыки, тувинцы)» (Тува - 73,2\%; Бурятия - 67,7\%; Калмыкия - 72,2\%);

«Буддизм - это одна из основных религий России» (Тува $-41,5 \%$; Бурятия $-29,1 \%$;

Калмыкия - 33,3\%);

- «Буддизм занимает важное место в российском цивилизационном пространстве России» (Тува $-12,5 \%$; Бурятия $-16,7 \%$; Калмыкия - 16,2\%);

- «Россия - единственная страна в Европе, в которой буддизм является традиционной религией» (Тува $-5,4 \%$; Бурятия $-6,8 \%$; Калмыкия $\left.-20,5 \%^{1}\right)$;

$2,6 \%$.

Как мы видим, традиционность стала наиболее определяющим фактором для большинства. Тем самым, можно констатировать, что в целом значительная часть студентов также отмечает прежде всего исторический аспект в данном терминологическом вопросе.

Интересная закономерность во мнениях установлена нами при выяснении понимания студентами какие из российских регионов можно назвать буддийскими. На вопрос «Какие регионы России считаются традиционно буддийскими?» мы предложили список территориальных образований для отметок, причем в нем были названы как действительно регионы, считающиеся буддийскими (Тува, Бурятия, Калмыкия и ряд краев), так и те, которые не считаются буддийскими (тем не менее со значительным этническим колоритом).

Свои регионы (регионы, где они живут и обучаются) молодежь склонна более определенно называть буддийскими, а вот в отношении других (тех, которые определяются большинством исследователей как буддийские) - не столь уверена в этом.

Например, тувинские студенты считают буддийскими регионами:

Туву $-96 \%$,

Бурятию - 89,7,

Калмыкию - 74,1\%.

Бурятские студенты считают буддийскими регионами:

Бурятию - 97,2\%,

${ }^{1}$ Здесь значительное число студентов Калмыкии объяснимо, поскольку в общественном дискурсе республики часто подчеркивается факт того, что калмыки - единственный буддийский народ в Европе. 
Туву $-58,6 \%$,

Калмыкию - 56,2\%.

Калмыцкие студенты считают буддийскими регионами:

Калмыкию - 98,3\%,

Бурятию - 84,6\%,

Туву $-65,8 \%$.

Также интерес представляет общее мнение молодежи всех трех регионов (по крайней мере четверти из опрошенных), что Якутию следует называть буддийским регионом: Тува $-25 \%$, Бурятия $31,9 \%$, Калмыкия - 18,8\%. В отношении остальных регионов мнения уже не столь многочисленные и определенные.

Также, несколько провокационный вопрос (о странах традиционного распространения буддизма) показал, что среди молодежи знания вопросов истории религии в целом (и истории буддизма в частности) не слишком четкие. Монголию - определенно буддийскую страну - таковой назвали в Туве лишь 51,3\% (что вызвало наше удивление), а вот в Бурятии и Калмыкии мнения более определенные $71,3 \%$ и 77\% соответственно. Только чуть более половины опрошенных в каждой республике назвали регионом распространения буддизма Индию (что, конечно, тоже весьма странно, учитывая то, что основы религиозной культуры, которые преподаются в школе, начинаются по теме буддизма с истории индийского принца Сиддхартхи Гаутамы - основателя буддизма): Тува $-61,2 \%$, Бурятия $56,6 \%$, Калмыкия - 54,3\%. В целом, ответы на этот вопрос показывают невысокий уровень знаний молодежью - жителями буддийских регионов - истории буддизма.

\section{Отночение к буддизму}

Вопросы, связанные с личным отношением к буддизму и личной оценкой роли буддизма в современном мире, вызвали вполне понятные положительные оценки у респондентов: Тува - 84\%; Бурятия - 67\%; Калмыкия - 80,3\% (таб. 6).

Таблица 6. Ответы на вопрос «Как Вы лично относитесь к буддизму?», в \% от числа опрошенных по каждому из регионов.

Table 6. Responses to the question, "What is your personal attitude to Buddhism?", \% of respondents by region.

\begin{tabular}{|l|l|c|c|c|}
\hline$N^{o}$ & \multicolumn{1}{|c|}{ Вариант ответа } & Тува & Бурятия & Калмыкия \\
\hline 1 & Положительно & 84,0 & 67,0 & 80,0 \\
\hline 2 & Безразлично & - & 29,0 & 17,6 \\
\hline 3 & Отрицательно & 2,0 & 1,0 & - \\
\hline 4 & Затрудняюсь ответить & 14,0 & 3,0 & 2,1 \\
\hline 5 & ИТОГО & 100 & 100 & 100 \\
\hline
\end{tabular}

Конкретизация тех аспектов буддизма, которые вызывают эти эмоции, была сделана в следующем вопросе «С чем для Вас ассоциируется буддизм?» с вариантами ответов, которых можно было выбирать несколько, а также указать свой вариант.

У большинства опрошенных студентов буддизм ассоциируется с:

— «верой, религией, ее последователями»: Тува - 64,7\%; Бурятия - 47,8\%; Калмыкия - 59,8\%;

- «народами, традиционно исповедующими буддизм; буддийскими странами»: Тува - 48,2\%; Бурятия - 58,6\%; Калмыкия - 56,8\%;

- «частью мировой культуры и истории»: Тува - 49,6\%; Бурятия - 49\%; Калмыкия - 60,7\%;

- «религиозной практикой, религиозными обрядами»: Тува $-25 \%$; Бурятия $-23,5 \%$; Калмыкия $31,2 \%$;

- «положительными суждениями»: Тува - 24,6\%; Бурятия $-21,1 \%$; Калмыкия - 35,5\%;

- «родственниками, знакомыми»: Тува - 17\%; Бурятия - 18,3\%; Калмыкия - 20,9\%.

Наибольшее число мнений получили первые три позиции. Ранжирование почти повторило ранжирование готовых, предлагаемых респондентам вариантов, поэтому отчасти этот порядок 
очевидно снова отразился на полученной картине. Мы можем только отметить, что молодежь рассматривает буддизм достаточно широко, не ограничиваясь представлением о том, что это ритуальная жизнь, которой живет близкий им социальный круг родственников и знакомых.

В любом случае широкий взгляд молодых позволил большинству более определенно оценить роль буддизма в современном мире (таб. 7 ). Положительной эту роль называют: в Туве $-83,5 \%^{1}$; в Бурятии $-70,9 \%$; в Калмыкии $-76,6 \%$, тогда как об отрицательной роли говорят единицы. Тем не менее, остальные (а это: $14,3,25,5$ и 22,6\% соответственно) все же затрудняются дать тот или иной ответ.

Таблица 7. Ответы на вопрос «По Вашему мнению, в современном мире буддизм играет положительную или отрицательную роль?», в \% от числа опрошенных по каждому из регионов.

Table 7. Responses to the question, "In your opinion, does Buddhism play a positive or negative role in the contemporary world?", \% of respondents by region.

\begin{tabular}{|c|l|c|c|c|}
\hline$N^{o}$ & \multicolumn{1}{|c|}{ Вариант ответа } & Тува & Бурятия & Калмыкия \\
\hline 1 & Положительную & 83,5 & 70,9 & 76,6 \\
\hline 2 & Отрицательную & 1,8 & 1,6 & 0,4 \\
\hline 3 & Затрудняюсь ответить & 14,3 & 25,5 & 22,6 \\
\hline 4 & Свой вариант ответа & 0,4 & 2 & 0,4 \\
\hline 5 & ИТОГО & 100 & 100 & 100 \\
\hline
\end{tabular}

\section{Буддизм как геополитический фактор}

Мы также попросили молодых людей оценить перспективы сотрудничества России со странами буддийского Востока - странами, где традиционно исповедуют буддизм (таб. 8).

Большинство ответивших считает, что между странами «Есть общие интересы в различных сферах (политика, геополитика, экономика, культура)»: Тува $-61,6 \%$; Бурятия $-57,4 \%$; Калмыкия $-63,7 \%$. В качестве оснований перспектив сотрудничества России и буддийского мира отметили «общие конфессиональные корни, которые могут послужить интеграции и сотрудничеству»: $38,4 \%$ в Туве; 40,6\% в Бурятии; 40,6\% в Калмыкии. Таким образом, студенты небезосновательно полагают, что буддийские народы России, являющиеся ее «внутренним Востоком» выступают своеобразным мостом, соединяющим Россию и буддийский мир.

Таблица 8. Ответы на вопрос «Как Вы оцениваете перспективы сотрудничества России со странами буддийского Востока (странами, где традиционно исповедуют буддизм)?», в \% от числа опрошенных по каждому из регионов.

Table 8. Responses to the question, "What do you think of the prospects of Russia's relations with the countries of the Buddhist East (countries where Buddhism is the prevalent religion)?”, \% of respondents by region.

\begin{tabular}{|c|l|c|c|c|}
\hline$N^{\circ}$ & \multicolumn{1}{|c|}{ Вариант ответа } & Тува & Бурятия & Калмыкия \\
\hline 1 & $\begin{array}{l}\text { Есть общие интересы в различных } \\
\text { сферах (политика, геополитика, } \\
\text { экономика, культура) }\end{array}$ & 61,6 & 57,4 & 63,7 \\
\hline 2 & $\begin{array}{l}\text { Есть общие конфессиональные } \\
\text { корни, которые могут послужить } \\
\text { интеграции и сотрудничеству }\end{array}$ & 38,4 & 40,6 & 6 \\
\hline 3 & Перспектив нет & 9,8 & 7,2 & 12,8 \\
\hline 4 & $\begin{array}{l}\text { Более перспективным является } \\
\text { сотрудничество со странами Запада }\end{array}$ & 8,5 & 12,4 & 1,2 \\
\hline 5 & Затрудняюсь ответить & 0,4 & 0,8 & \\
\hline 6 & Свой вариант ответа & & & \\
\hline
\end{tabular}

Прим.: Отмечать можно было несколько вариантов ответа. Также можно было вписать свой вариант ответа.

\footnotetext{
${ }^{1}$ См. также исследование о большом интересе к буддизму среди молодых тувинцев, которые его рассматривают как возможную детерминанту экономического развития тувинского общества: Тарбастаева, 2018.
} 
В то же время были даны и другие ответы:

- «Перспектив нет»: Тува - 9,8\%; Бурятия - 7,2\%; Калмыкия - 6\%;

- «Более перспективным является сотрудничество со странами Запада»: Тува $-8,5 \%$; Бурятия $12,4 \%$; Калмыкия $-12,8 \%$.

\section{Заключение}

Можно заключить, что буддизм, буддийский мир, буддийская культура воспринимаются студентами из российских буддийских регионов одинаково положительно. Буддизм для них большей частью ассоциируется с верой, религией, ее последователями, с народами, традиционно исповедующими буддизм, и буддийскими странами, как часть мировой культуры и истории. А российская евразийская идентичность, складывавшаяся на протяжении веков, воспринимается ими как органично интегрировавшая в себя культуры и конфесии всех народов России. Тем не менее, знание молодежью ряда аспектов истории и распространения буддизма явно недостаточное. Причем этот момент нам кажется требующим особого внимания в свете того, что речь идет о молодежи - представителях традиционно буддийских регионов страны.

Наши респонденты, характеризуя буддизм как органичную, неотъемлемую, часть российской истории, исторического наследия народов России, в большинстве своем положительно оценивают перспективы сотрудничества России со странами буддийского Востока (странами, где традиционно исповедуют буддизм). При этом своеобразным мостом, соединяющим Россию и буддийский мир, является ее «Внутренний Восток» - народы и регионы, относящиеся к буддийской культуре, буддийскому миру. Но все геостратегические вопросы невозможно решать без участия населения, без его информированности, знаний.

Соответственно, наше исследование показывает, что высокая религиозная идентификация молодежи имеет достаточно декларативный характер, нуждается в дополнительных исследованиях и последующей формулировки рекомендаций для образовательных программ и управленческих решений.

\section{Благодарности}

Коллектив авторов благодарит за любезное разрешение провести опрос студентов и содействие в организации опроса - руководство высших учебных заведений: О. М. Хомушку, ректора Тувинского государственного университета; А.А.Стороженко, проректора Тувинского государственного университета; В.Е. Сактоева, ректора Восточно-Сибирского государственного университета технологий и управления; К. Е. Бадмаеву, проректора Калмыцкого государственного университета имени Б. Б. Городовикова.

\section{СПИСОК ЛИТЕРАТУРЫ}

Анайбан, 3. В. (2017) Молодежь Тувы и Хакасии в ХХІ веке. М. : ИВ РАН. 240 с.

Бадмацыренов, Т. Б. (2016) Социология буддизма в России // Власть. № 6. С. 179-185.

Бадмацыренов, Т. Б., Родионов, В. А. (2014) Социология экономики буддизма: концептуальный анализ // Вестник Бурятского государственного университета. № 14-2. С. 49-54.

Базаров, Б. В. (2014) Буддизм и вызовы XXI века // Вестник Бурятского научного центра Сибирского отделения Российской академии наук. № 3 (15). С. 12-16.

Базаров, Б. В. (2015) Буддизм в условиях изменяющегося мира // Буддизм в контексте диалога культур: сборник статей / отв. ред. Л. Е. Янгутов. Улан-Удэ: Издательство Бурятского госуниверситета. 384 с. С. $8-15$.

Буддизм в контексте диалога культур: сборник статей (2015) / отв. ред. Л. Е. Янгутов. Улан-Удэ: Издательство Бурятского госуниверситета. 384 с.

Варнавский, П. (2011) «Национальная» религия в контексте глобализации: традиционный буддизм в современной Бурятии // Антропологический форум. № 14. С. 192-211. 
Кузьмин, С. Л. (2016) Буддизм как традиционная религия России: историческая основа и перспективы// Буддизм в третьем тысячелетии: тенденции и перспективы развития. Т. 1. Материалы Международной научной конференции (7-9 сентября 2016 г.) / отв. ред. М. М.-Б. Харунова, О. М. Хомушку. Кызыл : Изд-во ТувГУ. 216 с. С. 24-31.

Ламажаa, Ч. К. (2019) Геокультурные образы буддийского мира тувинцев: исторический контекст и современность [Электронный ресурс] // Новые исследования Тувы. № 3. URL: https://nit.tuva.asia/nit/ article/view/862 (дата обращения: дд.мм.гг.). DOI: 10.25178/nit.2019.3.3

Мчедлова, М. М. (2017) Религиозная и конфессиональная идентичность // Идентичность: Личность. Общество. Политика. Энциклопедическое издание / отв. ред. И. С. Семененко. М. : Весь Мир. 992 с. C. 334-339.

Островская, Е. А. (1999) Буддийские мирские общины Санкт-Петербурга // Социологические исследования. № 3. С. 107-113.

Островская, Е. А. (2018) Российская социология религии: религия общества (вступительная статья приглашенного редактора) // Мониторинг общественного мнения: Экономические и социальные перемены. № 2. C. 1-31. DOI: 10.14515/monitoring.2018.2.01

Пантин, В. И. (2017) Национально-цивилизационная идентичность // Идентичность: Личность. Общество. Политика. Энциклопедическое издание / отв. ред. И. С. Семененко. М. : Весь Мир. 992 с. C. $461-464$.

Синелина, Ю. Ю. (2009) Концепции секуляризации в социологической теории. Теоретические аспекты изучения религиозности населения в социологии религии. М. : ИСПИ РАН. 120 с.

Социология религии в обществе Позднего Модерна (памяти Ю. Ю. Синелиной) (2013) : материалы Третьей Международной научной конференции. НИУ «БелГУ», 13 сентября 2013 г./ отв. ред. С. Д. Лебедев. Белгород : ИД «Белгород». 460 с.

Тарбастаева, И. С. (2018) Буддийские ценности как возможная экономическая детерминанта развития тувинского общества [Электронный ресурс] // Новые исследования Тувы. № 2. URL: https:// nit.tuva.asia/nit/article/view/772 (дата обращения: 10.11.2019). DOI: 10.25178/nit.2018.2.5

Турман, Р. (2015) Вклад буддизма в глобальную цивилизацию в контексте современного мирового кризиса: где мы находимся? Что мы должны делать? Каковы перспективы успеха или поражения? // Буддизм в контексте диалога культур: сборник статей / отв. ред. Л. Е. Янгутов. Улан-Удэ: Издательство Бурятского госуниверситета. 384 с. С. 16-25.

Уланов, М. С. (2007) Буддизм в контексте глобализации // Государство, религия, церковь в России и за рубежом. Т. 25, № 1-2. С. 252-261.

Урбанаева, И. С. (2012) Буддийский вектор цивилизационного пограничья // Пограничье культур Культуры пограничья. - Debaty artes liberales. T. 4 / науч. ред. 3. Морохоева. Варшава : Druk ZakŁad Graficzny Uniwersytetu Warszawskiego. 307 c. C. 122-152.

Филатов, С. Б., Лункин, Р. Н. (2005) Статистика российской религиозности: магия цифр и неоднозначная реальность // Социологические исследования. № 6. С. 35-45.

Шестопал, Е. Б., Смулькина Н. В., Сорозикова, И. В. (2019) Сравнительный анализ образов своей страны у жителей российских регионов // Сравнительная политика и геополитика. Т. 10, № 3. С. 74-94. DOI: $10.24411 / 2221-3279-2019-10031$

Энциклопедический словарь социологии религии (2017) / под редакцией М. Ю. Смирнова. СПб. : Платоновское философское общество. 508 с.

Bell, I. (1979) Buddhist sociology: Some thoughts on the convergence of sociology and the Eastern paths of liberation // Scott, G., McNall, S. G. (Eds.) Theoretical perspectives in sociology. New York : St. Martin’s. 562 p. P. 53-68.

Leung, K. Z. (2017) Contemporary Youth Identity in the Republic of Tuva, Russia [Электронный ресурс] // Новые исследования Тувы. № 3. URL: https://nit.tuva.asia/nit/article/view/725 (дата обращения: 10.10.2019). DOI: $10.25178 /$ nit.2017.3.3

Schipper, J. (2012) Toward a Buddhist Sociology: Theories, Methods, and Possibilities // The American Sociologist. Vol. 43. Issue 2. P. 203-222.

Дата поступления: 18.11.2019 2. 


\section{REFERENCES}

Anaiban, Z. V. (2017) Molodezh' Tuvy i Khakasii v XXI veke. Etnosotsiologicheskie ocherki [Young people of Tuva and Khakassia in the twenty-first century: Ethno-sociological essays]. Moscow, MBA Publ. 240 p. (In Russ.).

Badmatsyrenov, T. B. (2016) Sotsiologiia buddizma v Rossii [Sociology of Buddhism in Russia]. Vlast', no. 6, pp. 179-185. (In Russ.).

Badmatsyrenov, T. B. and Rodionov, V. A. (2014) Sotsiologiia ekonomiki buddizma: kontseptual'nyi analiz [Sociology of the Buddhist economics: conceptual analysis]. Vestnik Buriatskogo gosudarstvennogo universiteta, no. 14-2, pp. 49-54. (In Russ.).

Bazarov, B. V. (2014) Buddizm i vyzovy XXI veka [Buddhism and the challenges of the third millennium]. Vestnik Buriatskogo nauchnogo tsentra Sibirskogo otdeleniia Rossiiskoi akademii nauk, no. 3 (15), pp. 12-16. (In Russ.).

Bazarov, B. V. (2015) Buddizm v usloviiakh izmeniaiushchegosia mira [Buddhism in a changing world]. In: Buddizm v kontekste dialoga kul'tur [Buddhism in the context of a dialogue of Cultures]: a collection of articles: / ed. by L. E. Iangutov. Ulan-Ude, Izdatel'stvo Buriatskogo gosuniversiteta. 384 p. Pp. 8-15. (In Russ.).

Buddizm v kontekste dialoga kul'tur [Buddhism in the context of a dialogue of Cultures] (2015): a collection of articles / ed. by L. E. Iangutov. Ulan-Ude, Izdatel'stvo Buriatskogo gosuniversiteta. 384 p. (In Russ.).

Varnavsky, P. (2011) «Natsional'naia» religiia v kontekste globalizatsii: traditsionnyi buddizm v sovremennoi Buriatii ['National' Religion in the Context of Globalization: Traditional Buddhism in Contemporary Buryatia]. Antropologichesky Forum, no. 14, pp. 192-211. (In Russ.).

Kuz'min, S. L. (2016) Buddizm kak traditsionnaia religiia Rossii: istoricheskaia osnova i perspektivy [Buddhism as a traditional religion in Russia: Historical foundation and prospects]. In: Buddizm v tret'em tysiacheletii: tendentsii i perspektivy razvitiia [Buddhism in the third Millennium: trends and prospects for development]. Proceedings of the international research conference (September 7-9, 2016) / ed. by M. M.-B. Kharunova and O. M. Khomushku. Kyzyl, TuvGU Publ. Vol. 1. 216 p. Pp. 24-31. (In Russ.).

Lamazhaa, Ch. K. (2019) Geocultural images of the Tuvan Buddhist world: historical context and modernity. The New Research of Tuva, no. 3 [online] Available at: https://nit.tuva.asia/nit/article/view/862 (access date: 10.11.2019). DOI: 10.25178/nit.2019.3.3

Mchedlova, M. M. (2017) Religioznaia i konfessional'naia identichnost' [Religious and confessional identity]. In: Identichnost': Lichnost'. Obshchestvo. Politika [Indentity. The individual, society, and politics]. An encyclopedia / ed. by I. S. Semenenko. Moscow, Ves' Mir. 992 p. Pp. 334-339. (In Russ.).

Ostrovskaia, E. A. (1999) Buddiiskie mirskie obshchiny Sankt-Peterburga [Buddhist lay communities of Saint Petersburg]. Sotsiologicheskie issledovaniia, no. 3, pp. 107-113. (In Russ.).

Ostrovskaya, E. A. (2018) Russian Sociology of Religion: Religion of Society (introductory article of the guest editor). Monitoring of Public Opinion: Economic and Social Changes, no. 2, pp. 1-31. (In Russ.). DOI: 10.14515/ monitoring.2018.2.01

Pantin, V. I. (2017) Natsional'no-tsivilizatsionnaia identichnost' [National and Civilizational identity]. In: Identichnost': Lichnost'. Obshchestvo. Politika [Indentity. The individual, society, and politics]. An encyclopedia / ed. by I. S. Semenenko. Moscow, Ves' Mir. 992 p. Pp. 461-464. (In Russ.).

Sinelina, Yu. Yu. (2009) Kontseptsii sekuliarizatsii v sotsiologicheskoi teorii. Teoreticheskie aspekty izucheniia religioznosti naseleniia $v$ sotsiologii religii [Concepts of secularization in sociological theory. Theoretical aspects of studying the religiosity of the population in the sociology of religion]. Moscow, ISPI RAN. 120 p. (In Russ.).

Sotsiologiia religii v obshchestve Pozdnego Moderna (pamiati Iu. Iu. Sinelinoi) [Sociology of religion in Late Modern society (in the memory of Yu. Yu. Sinelina)] (2013): proceedings of the Third International research conference, 13 September / ed. by S. D. Lebedev. Belgorod, «Belgorod» Publ.. 460 p. (In Russ.).

Tarbastaeva, I. S. (2018) Buddiiskie tsennosti kak vozmozhnaia ekonomicheskaia determinanta razvitiia tuvinskogo obshchestva [Buddhist values as a potential economic determinant in the development of Tuvan society]. The New Research of Tuva, no. 2 [online] Available at: https://nit.tuva.asia/nit/article/view/772 (access date: 10.11.2019). DOI: 10.25178/nit.2018.2.5. (In Russ.).

Turman, R. (2015) Vklad buddizma v global'nuiu tsivilizatsiiu v kontekste sovremennogo mirovogo krizisa: gde my nakhodimsia? Chto my dolzhny delat'? Kakovy perspektivy uspekha ili porazheniia? [The Contribution of Buddhism to global civilization in the context of the current global crisis: Where are we? What should we do? What are the prospects for success or failure? In: Buddizm v kontekste dialoga kul'tur [Buddhism in the context 
of the dialogue of Cultures]: a collection of articles / ed. by L. E. Yangutov. Ulan-Ude, Izdatel'stvo Buriatskogo gosuniversiteta. 384 p. Pp. 16-25. (In Russ.).

Ulanov, M. S. (2007) Buddizm v kontekste globalizatsii [Buddhism in the context of globalization]. State, Religion and Church, vol. 25, no. 1-2, pp. 252-261. (In Russ.).

Urbanaeva, I. S. (2012) Buddiiskii vektor tsivilizatsionnogo pogranich'ia [The vector of Buddhist civilization in the Borderlands]. In: Pogranich'e kul'tur - Kul'tury pogranich'ia. - Debaty artes liberales [Borderlands of Cultures - Culture of the Borderland. - Debaty artes liberales]. Vol. 4 / ed. by Z. Morokhoeva. Varshava, Druk ZakŁad Graficzny Uniwersytetu Warszawskiego. 307 p. Pp. 122-152. (In Russ.).

Filatov, S. B. and Lunkin, R. N. (2005) Statistika rossiiskoi religioznosti: magiia tsifr i neodnoznachnaia real'nost' [Statistics of Russian religiosity: the magic of numbers and ambiguous reality]. Sotsiologicheskie issledovaniia, no. 6, pp. 35-45. (In Russ.).

Shestopal, E. B., Smul'kina N. V. and Sorozikova, I. V. (2019) Sravnitel'nyi analiz obrazov svoei strany u zhitelei rossiiskikh regionov [Comparative analysis of one's own country images in Russian regions]. Comparative Politics Russia, vol. 10, no. 3, pp. 74-94. (In Russ.). DOI: 10.24411/2221-3279-2019-10031

Entsiklopedicheskii slovar' sotsiologii religii [An encyclopedic dictionary of the sociology of religion] (2017) / ed. by M. Yu. Smirnov. St. Petersburg, Platonovskoe filosofskoe obshchestvo. 508 p. (In Russ.).

Bell, I. (1979) Buddhist sociology: Some thoughts on the convergence of sociology and the Eastern paths of liberation. In: Scott, G., McNall, S. G. (Eds.) Theoretical perspectives in sociology. New York, St. Martin’s. 562 p. Pp. 53-68.

Leung, K. Z. (2017) Contemporary Youth Identity in the Republic of Tuva, Russia. The New Research of Tuva, no. 3 [online] Available at: https://nit.tuva.asia/nit/article/view/725 (access date: 10.10.2019). DOI: 10.25178/ nit.2017.3.3

Schipper, J. (2012) Toward a Buddhist Sociology: Theories, Methods, and Possibilities. The American Sociologist, vol. 43, issue 2, pp. 203-222.

Submission date: 18.11.2019. 